\title{
Innovative Means of Medical Students Teaching through Graphical Methods for Cardiac Data Estimating and Serious Games
}

\author{
Galya N. Georgieva-Tsaneva \\ Institute of Robotics, Bulgarian Academy of Sciences \\ Sofia, Bulgaria
}

\begin{abstract}
Now-a-days non-traditional methods and tools are introduced in the training of medical students which are mediated by the rapid development of information technologies: software training systems, Serious Games, and video materials. The paper presents a software system for the processing and analysis of physiological data, which is suitable for use in the medical students' training process and a study has been made of the use of serious games in medical education. For optimal work with a software system, a database of cardiac data has been created for healthy individuals and individuals with various cardiac diseases. The established system and the cardiology database can be used by medical doctors to study statistical parameters and graphical cardiac data representation in various diseases. The results obtained from the analysis of the data through graphical methods can be used as an effective visual means for increasing the success of medical students' training. The paper presents the results of a survey of the interest of medical students in higher education Universities in Bulgaria to the inclusion of Serious Games in their medical training. The results show a high interest in game-based learning: by including serious games such as innovative training, it will be possible to build on theoretical education and to increase the efficiency of the education process.
\end{abstract}

Keywords-Serious games; medical education; cardiovascular disease; heart rate variability; time domain analysis; spectrogram

\section{INTRODUCTION}

According to the World Health Organization, cardiovascular diseases are one of the most common causes of death in humans-most often by heart attacks, strokes, and hypertension. Average in the year over 17 million people die of cardiovascular disease, this is over 30\% of all deaths worldwide (in 2015: 17.7 million people, representing 31\% of all global deaths). In America, on average every 40 seconds, one person dies as a result of heart disease [1].

Healthy people have a heart rate that ranges from 60 to 100 beats per minute. On the activity of the heart, it affects the human brain, which activates the autonomic nervous system (ANS) with its 2 partitions-sympathetic and parasympathetic. The autonomic nervous system is a system that controls blood pressure, glands with internal secretion and body muscles. The sympathetic part of the nervous system accelerates heart rhythm, and the heart needs about 5 seconds to respond to this impact. Parasympathetic part of the nervous system reduces heartbeat and the heart responds is very quickly to this effect.
ANS is influenced by factors of various character - internal nature (age, body temperature, health status) and external nature (climatic conditions, body position, physical workload, stress factors). The nervous system stimulates the production of 2 hormones-cortisol and adrenaline. Adrenaline (acts quickly) increases heart rate, increases blood pressure, mobilizes energy reserves. Cortisol (acting more slowly) helps to supplement our energy resources, helps memory, and supports the immune system. There are many factors influencing heart activity: nervous system activity, day/night cycle, thermoregulation, etc. All external and internal factors affect heart activity, striving to achieve an inner balance in heart activity.

In the healthy heart, cardiac pulsations occur as a result of the operation of the sinus (sinoatrial) node, which permanently creates action potential, setting the rhythm of the heart. Therefore, in the normal functioning of the cardiovascular system of the human body, the heart rhythm is named a normal sinus rhythm.

Heart Rate Variability (HRV) is a tool for effective noninvasive ANS testing and the effect of ANS that has on cardiovascular system performance. The statistical and geometric parameters of HRV are the most commonly used means of HRV analyzing by researchers and physicians of cardiologists. The main purpose of this material is to study the parameters of HRV in the time domain of cardiac data of healthy and diseased individuals, comparative analysis and summaries.

The evaluation of the HRV parameters was carried out through a software program created by the author. The established software system and the base of various cardiac data can be used by medical students to study the impact of many cardiac diseases on statistical parameters of Heart Rate Variability and graphical depiction of HRV by histograms and spectrograms. A cardiological software system can be the basis for developing a serious game for the purpose of training students in medicine.

\section{A. Serious Games in the Education}

The use of serious educational games in student education is an innovative method by which learners are challenged to improve their knowledge, build up the learning material and seek new knowledge in the field they are studying. Serious games incorporated software and history that are united for learning purposes. Serious games have a dynamic character 
and are able to keep the attention of their users for a long time. Serious games can enhance students 'creativity, improve users' ability to take decisions in critical situations, and promote risktaking in decision-making. Like all other games and serious games cannot be played twice in the same way that allows for the development of creative and logical thinking. Much of the serious games are designed to be played in a team that helps develop the work of a team.

Rest of the paper is summarized as follow: Literature survey is shown in Section II. In Sections III Heart Rate Variability is presented. The use of serious games in medical education is presented in Sections IV. The experimental results are discussed in Sections V and VI respectively. Conclusion and future directions are presented in Section VII.

\section{RESEARCH BACKGROUND}

The interest of researchers in the study of Heart Rate Variability in recent years has grown exponentially. The HRV is not a separate physiological signal, it is derived from the electrocardiogram signal, recorded using various specialized devices: an electrocardiograph (used constantly in cardiology and recording short ECG signals-usually from 3 to 5 minutes); a Holter monitoring device (used less frequently when short records fail to show the nature of the cardiac problem and recording 24-hour long data). Historically, the first human electrocardiogram was published in 1887 by Augustus D. Waller, the first paper on paper was carried out in 1903 by the Dutch physiologist Willem Einthoven.

Lee [2] examines the HR variability in healthy people and patients with abnormal cardiograms. Studies of the HRV in the time domain make Drawz et al. [3], observing patients with chronic kidney disease and diabetic patients [4]. Surveys on 24-hour Holter Records of influence of the Age and Gender on the HRV are given in work [5]. The authors of [6-8] study the change in HRV due to various diseases.

A detailed overview of the results of several researchers' studies on HRV is presented in the book [9]. Detection and classification of cardiac intervals, statistical analysis of ECG and HRV in MATLAB environment are presented in [10]. The works $[11,12]$ are dedicated to the overall analysis of the HRV.

The analysis of ECG records is always preceded by a preprocessing of the data. The input cardiac records are subjected to the following treatments: denoising of the overlaid additional noise that hinders the next signal processing [13], reduction of the baseline drift, QRS complex detection. The authors of $[14,33]$ present effective methods of reducing noise and suppressing the drift of the baseline by methods of Empirical Mode Decomposition [14] and adaptive bionic wavelet transform [33].

A cardiac monitoring system for patients with cardiovascular diseases using a GSM module that transmits information on a risky situation is described in the work [15].
For research purposes, have been developed methods to simulate HRV sequences on which new algorithms can be tested for cardiac data processing and analysis [16].

The use of innovative Serious Games in education is a process that has grown in recent years around the world and is supported by technology development. Today, modern technology enters the classroom and offers new, interesting tools to improve the learning process, one of which is the use of serious learning games.

Annetta [17] gives the following definition of a serious game: "serious games are electronic/computer-access games that are not designed for commercial purposes but rather for training users on a specific skill set". According to Zuda [18], a serious game is състезания, "with specific rules, that uses entertainment to further government or corporate training, education."

Serious games in education have one of two purposes [19]: solving a problem or simulating events from the real world, thanks to which different skills develop.

According to Presky [20], serious games are a very good opportunity to engage learners in the training process.

Serious games evolve over time; they can now be used on different platforms [21].

\section{HEART RATE VARIABILITY}

Heart Rate Variability is a modern diagnostic parameter that is produced by non-invasive methods on human subjects. Its application in clinical medical practice is regulated through the adoption of an HRV standard by the European Society of Cardiology and the North American Society of Pacing and Electrophysiology (1996) [22].

The reducing of the Heart Rate Variability after acute myocardial infarction is a sign of a serious health disorder in the individual's body [23] The authors of [24] found a link between the severely reduced HR variability and the increased probability of death after myocardial infarction. In the scientific literature, a correlation between the significantly reduced values of the statistical parameters of the HRV has been found [25] and sudden cardiac death [26]. Studies of various diseases of the cardiovascular system (heart failure, Ventricular arrhythmia, coronary artery disease, diabetes neuropathies, arterial hypertension, etc.) often include HRV analysis. Studies on the causes of Chronic Atrial Fibrillation include HRV analysis [8]. Not least, the ANS response to various physiological stresses and psychological effects can be assessed by HRV analysis. Hence, HRV research can provide valuable information to cardiological doctors about the impact of the patient's treatment process and on the body's internal abilities to cope with the illness problem.

The HRV analysis is based on determining the time sequences between the adjacent highest $\mathrm{P}$ peaks in the graph of the ECG signal. This analysis can provide information on the 
functional state of the person and to monitor the dynamics of his change. Surveys in the time domain are divided into calculating statistical parameters and determining geometric parameters. There are two approaches to calculating the time parameters: calculations on the entire continuous record and calculations on small parts of it [22]. The statistical parameters to be determined on the basis of long - term Holter ECG records are [22]:

- Parameters calculated directly from normal intervals.

- Parameters based on differences between successive NN intervals.

For purposes of this study, the input HRV data were obtained through a Holter monitoring performed on sick and healthy individuals. Holter devices retain continuous 24-hour ECG recordings. Before the data are used, these records are decompressed and pre-processing. This includes noise reduction [27], reduction of the drift of the baseline, localization of the QRS complex [28]. Then RR time intervals are obtained, ectopic intervals are excluded and $\mathrm{NN}$ time intervals (derived from sinus node depolarizations [29]) are obtained.

Time domain analysis measures changes in heart rate depending on the time parameter or measures the intervals between consecutive normal heart cycles. The calculated time domain parameters are as follows:

- RR intervals minimum, maximum and mean values;

- heart rate minimum, maximum and mean values;

- standard deviation calculated on the lengths of normal cardiac intervals: SDNN, SDANN, SDindex;

- the standard deviation of heart rate SDhr;

- the parameters RMSSD, NN50, pNN50, and others.

From the statistical parameters, the standard for HR variability recommends the study of SDNN, SDANN, and RMSSD [22]. The formulas for calculating the statistical parameters, as well as explanations of their character are presented in Table I.
In the geometric analysis of HRV, the normal intervals are represented by a histogram of the distribution of the density of the differences between the successive normal intervals [22]. From the distribution represented on the corresponding histogram, it can be judged about the length of the more frequent intervals in the HRV sequence. Intervals, which are much shorter or longer than normal intervals, can easily be seen on the histogram - they fall outside the main peak of the triangular histogram and can thus be identified.

Geometric parameters are:

- HRVTi: HRV triangular index;

- TINN: triangular index of normal NN intervals;

- Lorenz plot of normal intervals.

Geometric parameters of HRV are presented in Table I. From the geometric parameters, the HR variability standard recommends the HRVTi study [22]. Reference (normal) values of parameters (Statistical and Geometrical) in the time domain for healthy individuals [22] are presented in Table II.

In the time domain, apart from calculating the abovementioned parameters, histograms of normal cardiac intervals and heart rate histograms are also drawn. The histogram is a graphical representation of HRV: time-dependent distribution of duration of RR sequences. Fig. 1 shows a graph of normal cardiological intervals and an individual with normal sinus rhythm, and Fig. 2 shows a graph of an individual with cardiovascular disease. The lengths of the HRV intervals of the healthy individual are distinguished by a higher variation than the lengths of the intervals in the diseased individual. The lengths of the intervals in Fig. 2 are located in a narrower overall width, the series looks more even, and the adjacent intervals are of a near length. The cardiac rhythm of patients with cardiovascular disease has small variations. When an unexpected event occurs, the body reacts by increasing or decreasing its heart rate and in this way it adapts to the changes. In the presence of stress or fright, the healthy heart reacts by accelerating its rhythm, but soon the rhythm returns to its normal values. In ill individuals, the accelerated rhythm is retained and is usually required medication to reduce heart rhythm.

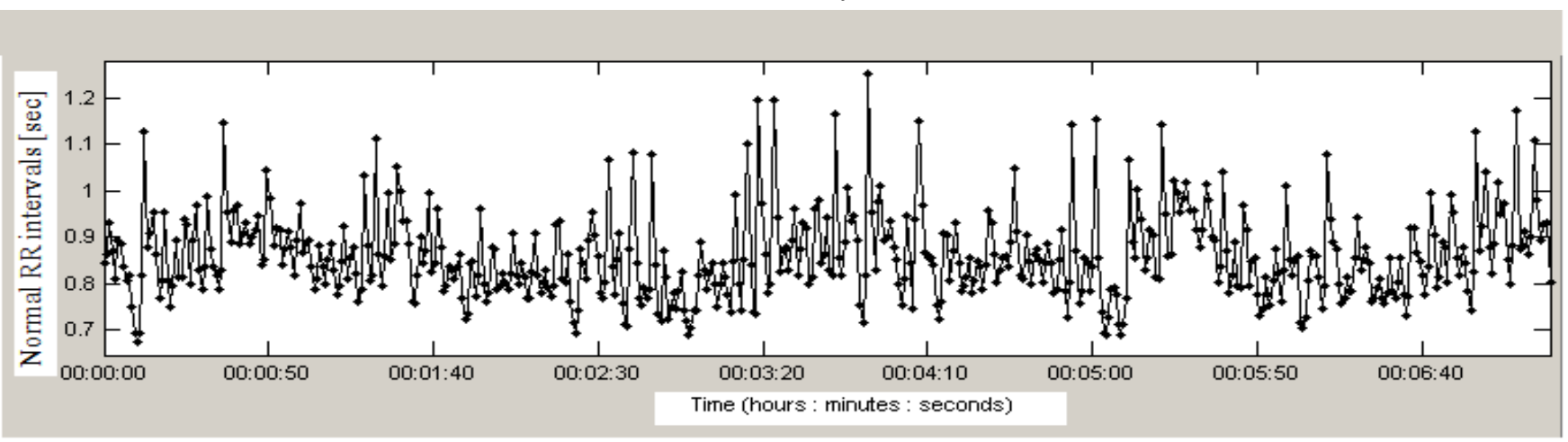

Fig. 1. Normal Cardiological Intervals (an Individual with Normal Sinus Rhythm). 


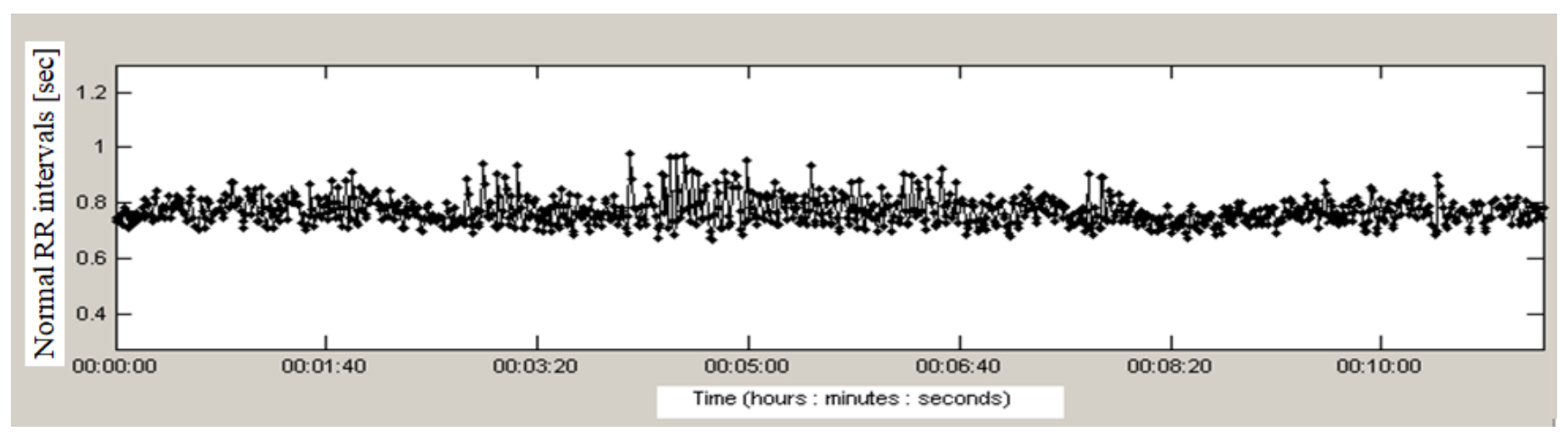

Fig. 2. Normal Cardiological Intervals (an Individual with Cardiovascular Disease).

TABLE I. Statistical and Geometrical Parameters in the Time Domain [22], [ 30]

\begin{tabular}{|c|c|c|}
\hline Parameter [units ] & Formula & Description and relations \\
\hline \multicolumn{3}{|l|}{ Statistical parameters } \\
\hline RR Mean [ms] & $\overline{R R}=\frac{1}{N} \sum_{i=1}^{N} R R_{i}$ & \multirow{2}{*}{$\begin{array}{l}\text { Mean value of RR intervals. } \\
\text { Standard deviation (SD) of heart rate over the entire measurement period. }\end{array}$} \\
\hline HR Mean [bpm] & $H R$ Mean $=\sqrt{\frac{1}{N-1} \sum_{i=1}^{N}\left(H R_{i}-\overline{H R}\right)^{2}}$ & \\
\hline SDNN [ms] & $S D N N=\sqrt{\frac{1}{N} \sum_{i=1}^{N}\left(R R_{i}-\overline{R R}\right)}$ & $\begin{array}{l}\text { Estimates NN-intervals standard deviation in the whole ECG record or parts of it. Estimates } \\
\text { overall HRV.Gives information about all cyclical components that affect the dynamics of } \\
\text { normal intervals in ECG over the estimated period of the record. Also reflects the slow reaction } \\
\text { of the heart to the hormones. Parameter values grow as the record length increases. }\end{array}$ \\
\hline SDANN[ms] & $S D A N N=\sqrt{\frac{1}{N} \sum_{i=1}^{N}\left(\overline{R R_{\iota}}-\overline{\overline{R R}}\right)^{2}}$ & $\begin{array}{l}\text { SD of the averages normal time intervals over five-minute segments calculated. Estimates long- } \\
\text { term fluctuation. Reflects circadian rhythmicity of autonomic function. }\end{array}$ \\
\hline RMSSD $[\mathrm{ms}]$ & $R M S S D=\sqrt{\frac{1}{N-1} \sum_{i=1}^{N-1}\left(R R_{i+1}-\overline{R R_{l}}\right)^{2}}$ & $\begin{array}{l}\text { The square root of the mean of the sum of the squares of successive differences between NN } \\
\text { intervals [31].Short-term records obtaining. Measured short term variation. Reflects high- } \\
\text { frequency variations and parasympathetic regulation of the heart. }\end{array}$ \\
\hline SDNN index [ms] & $S D N N_{\text {index }}=\frac{1}{N} \sum_{i=N}^{N} S D N N_{i}$ & $\begin{array}{l}\text { It is the mean of the standard deviations of all NN intervals for each five-minute segments of the } \\
\text { entire recording. The Index is measured autonomic influence on HRV. }\end{array}$ \\
\hline NN50 [count] & 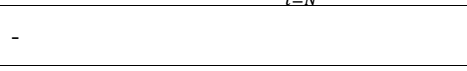 & $\begin{array}{l}\text { Represents the number of adjacent } \mathrm{NN} \text { intervals differing by more than } 50 \mathrm{~ms} \text { It gives an idea of } \\
\text { the dynamics between adjacent normal intervals-measured short term variation. }\end{array}$ \\
\hline pNN50 [\%] & $p N N 50=\frac{N N 50}{N N} \cdot 100 \%$ & $\begin{array}{l}\text { Percentage of successive normal intervals }>50 \mathrm{~ms} \text {. The ratio of the number of adjacent NN } \\
\text { intervals differing by more than } 50 \mathrm{~ms} \text { (NN50) to the total number of NN intervals multiplied by } \\
100 \text {. }\end{array}$ \\
\hline \multicolumn{3}{|l|}{ Geometric parameters } \\
\hline HRVTi [-] & $H R V T i=\frac{\sum_{i=1}^{N_{b}} b\left(t_{i}\right)}{\max _{i} b\left(t_{i}\right)}=\frac{N-1}{\max _{i} b\left(t_{i}\right)}$ & $\begin{array}{l}\text { Calculated on the basis of the previously constructed histogram. Overall Heart Rate Variability } \\
\text { estimation. Dependent on the length of the bin [32]. }\end{array}$ \\
\hline TINN [ms] & Interpolation procedure. & Overall Heart Rate Variability estimation. \\
\hline \multicolumn{3}{|c|}{$\begin{array}{l}N \text { - number of all intervals; } i \text {-index; } \\
\overline{R R} \text { - an average of all RR intervals; } \overline{R R_{l}} \text { - mean value of RR intervals in the segment; } \\
b-\text { bin corresponding to time } t_{i} ; N_{b}-\text { number of bins; } \\
\overline{\overline{R R}} \text { - mean value of all RR averages overall 5-minute segments, M-number; } \\
\overline{\mathrm{HR}} \text { - an average of all HR. }\end{array}$} \\
\hline
\end{tabular}

TABLE II. REFERENCE VALUES OF PARAMETERS IN THE TIME DOMAIN [22]

\begin{tabular}{|c|c|c|c|}
\hline Parameter & Normal values $($ mean \pm sd) & Units & Note \\
\hline HRmin & $>50$ & bpm & \multirow{6}{*}{$\begin{array}{l}\text { High levels are a symptom of } \\
\text { high HRV, low levels - of low } \\
\text { HRV }\end{array}$} \\
\hline HRmax & $<120$ & bpm & \\
\hline SDNN & $141 \pm 39(102-180)$ & $\mathrm{ms}$ & \\
\hline SDANN & $127 \pm 35(92-162)$ & $\mathrm{ms}$ & \\
\hline RMSSD & $27 \pm 12(15-39)$ & $\mathrm{ms}$ & \\
\hline HRV Triangular Index & $37 \pm 15(22-52)$ & - & \\
\hline
\end{tabular}




\section{Using SERIOUS GAMES IN MEdicAl EdUCATION}

Serious games are competition, story, art, and software. In medical education, serious games are tools to reinforce the learning material, to test the learning and to acquire new knowledge. The use of simulation games in medical training makes it possible to learn new skills in a safe environment, to create an experience for a given medical manipulation or activity (for example, injection, blood pressure measurement, diagnosis, the appointment of laboratory tests). The use of serious games in medical education enables students to place themselves in a virtual environment close to the real environment one in which to examine a patient, identify his disease, and arrange treatment. The purpose of such a serious game is the virtual healing of the patient by the viral physician. The mistakes that a student can make will not affect a real patient, so the game is also safe for patients, and it is a valuable experience that students can acquire in their training and then use it in their practice of medics.

The serious medical game can be created in a way, that allows increasing the level of complexity in the game, when established user progress. When a user successfully make the treatment of a virtual patient and the patient is healing, the student may be faced with a more complex situation-a clinical case for which greater skill is required, and the consideration of more objective facts. Some of the medical training games offer the opportunity to take different roles from the user (student, trainee, specialist, and head of the hospital ward) and so the user learns how to act, what are his responsibilities, according to the role he has taken.

Serious education games in medical training offer the opportunity to acquire valuable experience, increase student motivation, and give feedback quickly to the knowledge and skills of their users.

\section{REsults}

The created cardiac record database contains over 1100 records of patients with various cardiological diseases and records of healthy individuals. The records are 24-hour records of heart activity obtained with Holter monitoring and received from the Multiprofile Regional Hospital for Active Treatment "Dr. Stephen Cherkezov", Veliko Tarnovo, Bulgaria.

Characteristics of patients. Investigations were performed on 116 Holter Records of 3 groups of Individuals (Individuals with Sinus Bradycardia, Ventricular Fibrillation, and Individuals with Normal Sinus Rhythm). Their demographic characteristic (the age and gender distribution, the mean age of subjects) is shown in Table III. Values of parameters are expressed as mean \pm standard deviation (SD) or in percent $(\%)$. There is no significant difference between the different groups according to Gender and Age.

The heart rate variability analysis is done in the time domain using an author's software program. Analyzed records were obtained during the daily life of individuals using the Holter monitoring method. Individual recordings can be recorded locally on the computer or downloaded from a remote server. The software is implemented in a MATLAB programming environment. The tested parameters were determined according to the formulas shown in Table I and following the recommendations of the standard for the HRV.

Fig. 3 shows the histograms made on the recordings of healthy subjects with normal sinus rhythm. The distribution of normal cardiac intervals is central, with the largest percentage of the intervals being located in a few columns around the tachogram mod (with cardiac intervals of 0.45 to $1 \mathrm{sec}$ ). At the same time, there are intervals of different sizes, located in both the smaller values and the larger values of the interval lengths.

Fig. 4 shows histograms of patients with Ventricular Fibrillation. The distribution of intervals is a wider range, the basis of the histogram is of normal width.

Sinus bradycardia (heart rate $>100 \mathrm{bpm}$ ) is presented in Fig. 5, there is a shifting of the histogram mod (the most frequent value of intervals in the histogram) to the right and a presence of a small number of high columns.

TABLE III. DEMOGRAPHIC CHARACTERISTIC

\begin{tabular}{|l|l|l|l|l|}
\hline $\begin{array}{l}\text { Para- } \\
\text { meter }\end{array}$ & $\begin{array}{l}\text { SB } \\
\mathbf{n = 4 8}\end{array}$ & $\begin{array}{l}\text { VF } \\
\mathbf{n = 3 6}\end{array}$ & $\begin{array}{l}\text { NSR } \\
\mathbf{n = 3 2}\end{array}$ & P value \\
\hline $\begin{array}{l}\text { Gender, } \\
\text { Men \% }\end{array}$ & 51.06 & 54.48 & 53.13 & NS \\
\hline Age \pm SD & $63.11 \pm 22.08$ & $63.94 \pm 28.46$ & $52.46 \pm 24.18$ & NS \\
\hline
\end{tabular}

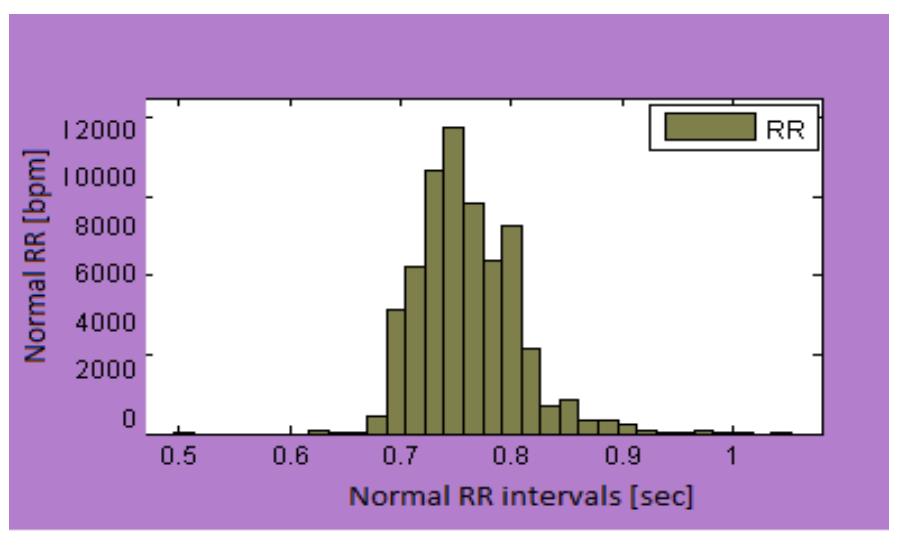

Fig. 3. A Healthy Individual.

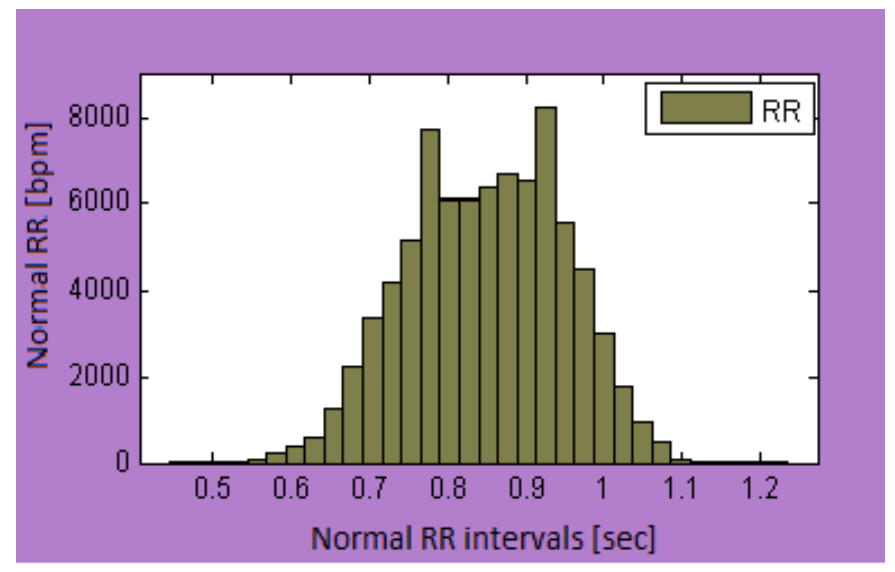

Fig. 4. Ventricular Fibrillation. 


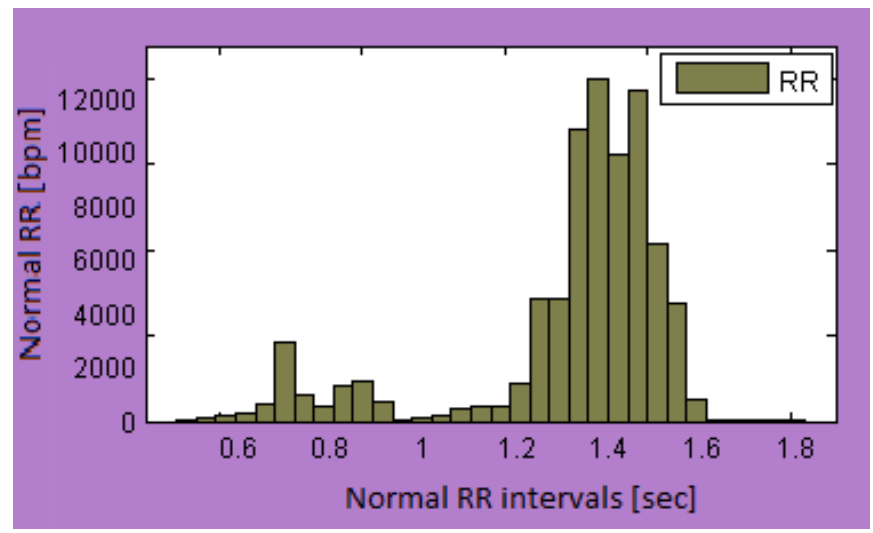

Fig. 5. Sinus Bradycardia.

Table IV presents the average results of the defined statistical and geometric parameters of HRV analysis obtained from the study of several groups of Individuals (total number 116): Individuals with normal sinus rhythm (NSR); Individuals with Ventricular Fibrillation (VF), Sinus Bradycardia (SB). The results are presented as mean \pm standard deviation (mean \pm sd). The values of the parameters of the study groups were tested by the ANOVA test.

The assessments of the mean value of normal cardiac intervals and the mean heart rate indicate that these parameters are not statistically significant ( $>0.05)$. Their mean values, however, are determinant in the diagnosis of sinus bradycardia (mean HR < 60, mean RR $>1000 \mathrm{~ms}$ ). From time domain parameters studied, the values of statistical deviations SDNN $(\mathrm{p}=0.026)$, SDANN $(\mathrm{p}=0.019)$ have statistical significance $(\mathrm{p}<0.05)$. In the studied groups of patients, there was a tendency to decrease of these two parameters compared to individuals with normal heart rhythm and compared to the reference values recommended by the standard. In individuals with sinus bradycardia, the opposite trend is observed - the SDNN and SDANN values are higher than those of normal sinus rhythm individuals. Therefore, there is an increase in HRV in patients with sinus bradycardia. RMSSD values are significantly reduced in individuals with Ventricular Fibrillation while those with Sinus Bradycardia are significantly elevated. Studies have shown that the pNN50 parameter has statistical significance, and in individuals suffering from different diseases, it has higher values than in healthy individuals. Of the two studied geometric parameters, HRVTi has statistical significance. TINN values are not statistically significant $(\mathrm{p}=0.117)$ and are highest in healthy controls.

The results of the study groups of individuals are also depicted using a spectrogram method-a graphical method of displaying the spectrum of frequencies of a signal dependent of the time. Three methods are used in the training software program to generate a spectrogram: Burg Periodogram; LombScargle Periodogram and Wavelet method.

Fig. 6 shows a spectrogram of a healthy individual obtained by the wavelet method. Heart Rate Variability in healthy individuals is high and indicates their ability to respond appropriately to environmental changes, stress, and other adverse effects. In Low Frequency $(0.04-0.15 \mathrm{~Hz}, \mathrm{LF})$ and
High Frequency $(0.15-0.4 \mathrm{~Hz}, \mathrm{HF})$ area (in the spectrogram) predominate the following colors: yellow, orange and red, which represent the high power values of the studied signal. Fig. 7 and Fig. 8 show spectrograms of individuals with cardiovascular disease. The signal power at LF and HL area is low (depicted using large blue fields): low heart rate variability, the indicator for of poor health of the individual.

- Application of the software system in the medical education process

Students' training, including a graphical presentation of the results of various cardiac disease records, aims to develop students' creative thinking and to create visual imagination related to different types of cardiac diseases, which will increase their motivation for learning and will be another a method of strengthening knowledge and increasing the success rate of the discipline.

TABLE IV. PARAMETERS IN THE TIME DOMAIN

\begin{tabular}{|c|c|c|c|c|}
\hline $\begin{array}{l}\text { Para- } \\
\text { meter }\end{array}$ & $\begin{array}{l}\text { SB } n=48 \\
(\text { mean } \pm \text { sd })\end{array}$ & $\begin{array}{l}\text { VF } n=36 \\
(\text { mean } \pm \text { sd })\end{array}$ & $\begin{array}{l}\text { NSR } n=32 \\
(\text { mean } \pm \text { sd })\end{array}$ & $\begin{array}{l}\text { P value } \\
\text { mean } \pm \text { sd }\end{array}$ \\
\hline $\begin{array}{l}\text { Mean RR } \\
{[\mathrm{ms}]}\end{array}$ & $\begin{array}{l}1016.01 \pm \\
424.87\end{array}$ & $\begin{array}{l}841.07 \pm \\
294.92\end{array}$ & $\begin{array}{l}840.14 \pm \\
387.68\end{array}$ & $\begin{array}{l}\text { NS } \\
(0.053)\end{array}$ \\
\hline $\begin{array}{l}\text { Mean HR } \\
{[\mathrm{bpm}]}\end{array}$ & $\begin{array}{l}59.82 \pm \\
26.64\end{array}$ & $72.65 \pm 32.92$ & $\begin{array}{l}73.48 \pm \\
28.73\end{array}$ & NS $(0.061)$ \\
\hline $\begin{array}{l}\text { SDNN } \\
{[\mathrm{ms}]}\end{array}$ & $\begin{array}{l}142.32 \pm \\
11.08\end{array}$ & $132.97 \pm 14.93$ & $\begin{array}{l}139.4 \pm \\
21.17\end{array}$ & $\begin{array}{l}<0.05 \\
(0.026)\end{array}$ \\
\hline $\begin{array}{l}\text { SDANN } \\
{[\mathrm{ms}]}\end{array}$ & $\begin{array}{l}136.8 \pm \\
19.06\end{array}$ & $124.43 \pm 18.72$ & $\begin{array}{l}129.02 \pm \\
22.51\end{array}$ & $\begin{array}{l}<0.05 \\
(0.019)\end{array}$ \\
\hline $\begin{array}{l}\text { SDindex } \\
{[\mathrm{ms}]}\end{array}$ & $62.17 \pm 4.13$ & $61.99 \pm \quad 6.14$ & $62.13 \pm 3.78$ & NS (0.985) \\
\hline $\begin{array}{l}\text { RMSSD } \\
{[\mathrm{ms}]}\end{array}$ & $32.47 \pm 6.09$ & $29.62 \pm \quad 8.73$ & $29.07 \pm 2.03$ & $\begin{array}{l}<0.05 \\
(0.035)\end{array}$ \\
\hline $\begin{array}{l}\text { pNN50 } \\
{[\%]}\end{array}$ & $\begin{array}{l}24.4 \pm \\
18.6\end{array}$ & $25.71 \pm 12.06$ & $16.39 \pm 11.04$ & $\begin{array}{l}<0.05 \\
(0.023)\end{array}$ \\
\hline HRVTi & $21.43 \pm 4.06$ & $19.4 \pm 6.7$ & $22.27 \pm 2.02$ & $\begin{array}{l}<0.05 \\
(0.034)\end{array}$ \\
\hline $\begin{array}{l}\text { TINN } \\
{[\mathrm{ms}]}\end{array}$ & $\begin{array}{l}448.2 \pm \\
171.4\end{array}$ & $485.7 \pm 181.43$ & $\begin{array}{l}516.37 \pm \\
109.63\end{array}$ & 0.172 \\
\hline
\end{tabular}

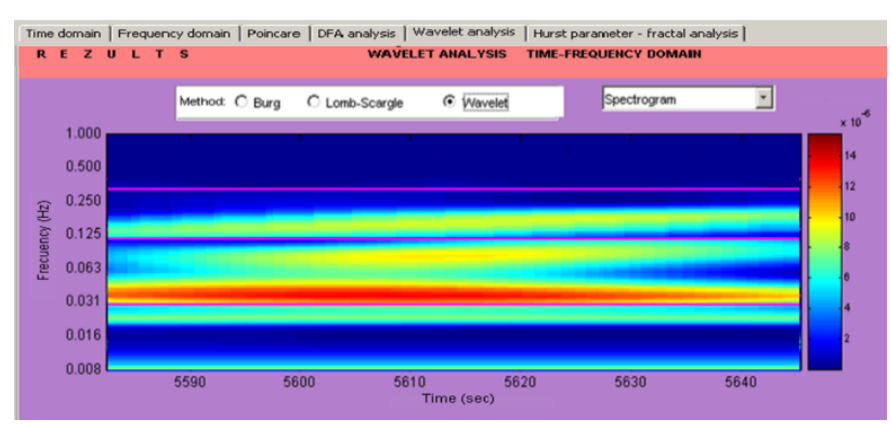

Fig. 6. Spectrogram of Normal HRV. 


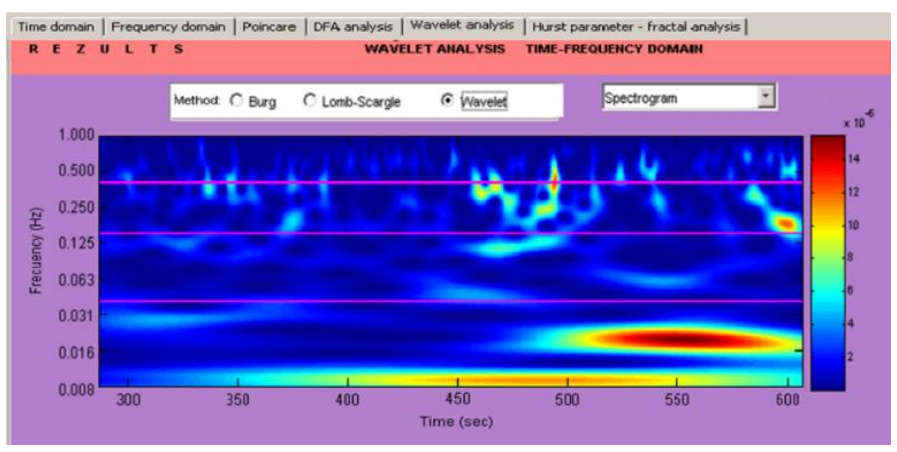

Fig. 7. Spectrogram of abnormal HRV (Ventricular Fibrillation).

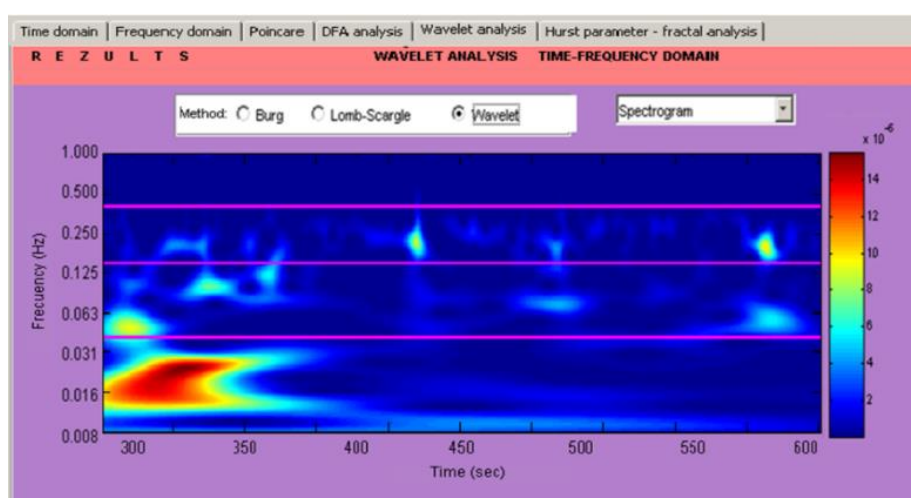

Fig. 8. Spectrogram of abnormal HRV (Sinus Bradycardia).

The created software system allows the selection of data records of patients with various diseases, calculation of the statistical parameters of cardiac records (time domain parameters of HRV) and the graphic results of the research results. The resulting histograms and spectrograms illustrate the heart rate variability through the rich-colored figures.

- Results of research on the use of Serious Games in medical education in Bulgaria

The use of serious games in the education process is a relatively new direction in the pedagogical aspect. Traditional education needs a change to meet the requirements of the modern technological age and the requirements of the students themselves, whom today work freely with new technologies, process varied information in a short time and are oriented towards technological innovation. A very good idea is the presentation of the medical material through serious games, which will give a different view of the taught knowledge. Technological approach to education is inevitable, given the pervasive introduction of technology into people's everyday lives.

The established software system is a tool for effective medical students' training, which makes it possible, through repeated use, to remember imperceptibly and long lasting many basic parameters of the HRV, which can help future medical specialists to diagnose patients. Additionally, the established system having cardiac storage and distribution module based on their underlying diagnosis can be used to store actual patient data and refer to a subsequent visit to create an electronic history of the disease in which also store Holter records and numerical and graphical results.
The presented software system can also be developed in the form of a serious game to be used by students in their preparation for their cardiology specialty. The creation of a serious training game is one of the goals of a program that works to create effective training tools for medical students.

A survey was conducted among 162 medical students in Universities in Bulgaria, which aims to explore the interest of students in the inclusion of serious education games in their training. The survey was conducted among a small number of respondents, but the results obtained were interesting and indicative.

Fig. 9 shows the results of the answer to the question "Do you want serious games to be used in university training?" Most respondents $(96.3 \%)$ have answered YES, only 1 respondent has answered NO, and $2.1 \%$ said: "I cannot decide". The results obtained show a great interest of the students to include serious games in the educational process as an opportunity for further build on of the learning material and improving the knowledge and skills of the subjects.

Fig. 10 shows the results of the survey of respondents about their preferences for various types of serious games. The question makes it possible to indicate more than 2 responses. A predominant percentage of respondents want to use competitive games $(69.1 \%)$, which shows a striving for development in a competitive environment. $50.6 \%$ prefer to play adventure games, which is an indication of interest in learning with creative, entertaining elements. $40.7 \%$ of respondents want to playtest games, believing that they will help to better learn the learning material.

The answers of respondents to this question show a great interest in various types of serious games that enable teachers to choose the appropriate Serious Games among a wide range of type of learning games by matching what kind of serious game is best suited to the specific pedagogical goals in the learning process.

The survey conducted included a question about the possibility of including serious games with virtual reality in student education (see Fig. 11). Most respondents (140 of all 162 students) has answered YES, 18 has answered: "I cannot decide", and only 1 student has answered NO. The answers to this question indicate students' readiness to use serious games with virtual reality in their training. These serious educational games can improve a number of medical skills of students through virtual simulations.

\section{Do you want serious games to be used in the university training?}
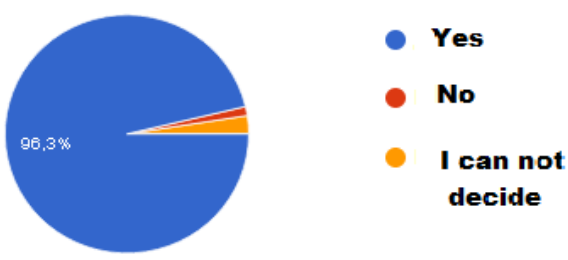

162 answers

Fig. 9. Exploring the Interest in Serious Educational Games. 


\section{What serious games you prefer to} play?

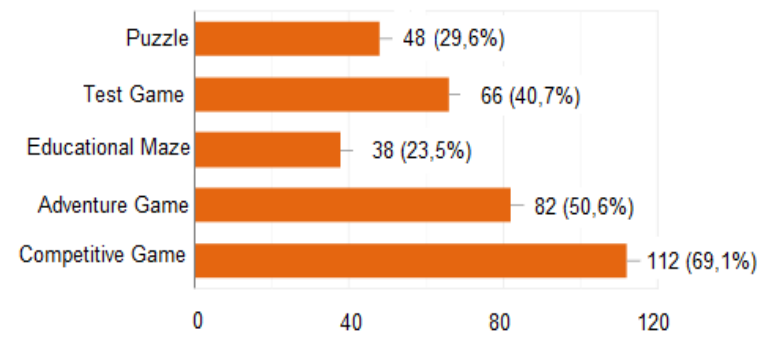

162 answers

Fig. 10. Exploring the Interest in the Types of Serious Educational Games.

\section{Do You want to be given the opportunity to learning through Serious Games with virtual reality?}
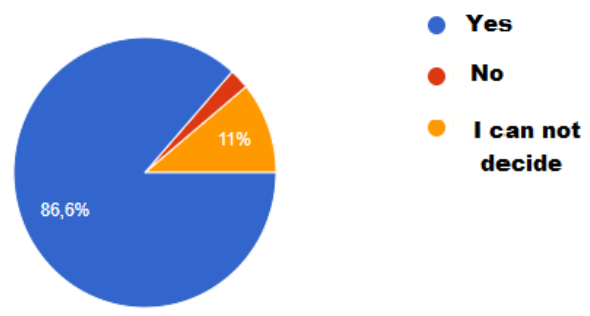

162 answers

Fig. 11. Exploring the Interest in Serious Games with Virtual Reality.

The study shows a high interest from students to various types of serious educational games, which shows the possibility of introducing various innovative games in the medical education, according to the study material and the medical skills that the students have to acquire.

The survey and its results can be used to improve the education process in Universities with medical specialties. The study shows that the inclusion of serious educational games in medical training is an innovative method provided by the development of information technology that students will use with interest.

\section{DisCUSSION AND FUTURE SCOPE ON THE USE OF SERIOUS GAMES IN TRAINING}

Serious educational games today are the focus of many researchers and lecturers. The study conducted among medical students in Universities in Bulgaria shows great interest in the use of serious educational games for the purposes of their medical education. Research on the use of serious games in student education in the medical learning process in many countries around the world shows that serious games play a significant role studying them and in teaching new materials. At the same time, the study conducted among Bulgarian students shows a considerable interest in the use of serious games and their inclusion in the learning education process.

The author's future work in this direction may include exploring the possibilities for including serious games in medical education in Bulgaria: is there a necessary material and technological base in medical Universities in order for serious games to be brought into the learning process in medical higher education.

An important issue in using serious games is whether teachers themselves are willing and willing to use serious games in the learning process, and what pedagogical impacts may be in using serious games. The interest of Bulgarian students of serious games, the increase in the use of serious games in the world's Universities shows an inevitable tendency: serious games are entering into the learning process, the prerequisites for this are present, technologies are constantly developing and marking high growth in recent years, that the necessary technical resources for the use of serious games will be available.

In conclusion, the following can be noted: the use and consolidation of the serious educational games in the educational process is a significant trend that will mark a new direction in the development of education both in the world and in Bulgaria.

\section{CONCLUSION}

The paper presents a software system for processing and analyzing cardiac data that can be used in medical education to extend students' knowledge and learn additional information about HRV statistical parameters. The software system enables the study of cardiac data of healthy individuals and patients with various cardiac diseases. The results obtained are presented graphically and numerically. The graphical way allows for the visual perception of the results obtained and the creation of links between visual methods of acquiring knowledge and traditional learning methods.

The survey among 162 students in Bulgaria shows an increased interest of respondents to include serious educational games in medical education in Bulgaria. The results show that the inclusion of serious games in training seems attractive to students. A high percentage of respondents declare their preference to use serious games in their education that have a competitive $(69.1 \%)$ and adventure $(50.6 \%)$ element. Having a predefined scenario (story) is an additional element to increase the attractiveness of the serious game.

\section{ACKNOWLEDGMENT}

This work was supported by the Bulgarian Ministry of Education and Science under the National Research Program "Young scientists and postdoctoral students" approved by DCM \# 577 / 17.08.2018 and NSF of Bulgaria under the Research project № DM 12/36/20.12.2017, "Investigation of Mathematical Techniques of Analysis of Physiological Data with Functionality for People with a Visual Deficit." 


\section{REFERENCES}

[1] E. Benjanim, S. Vinary, C. Callaway, A. Chamberlain, A. Chang, S Cheng, etc. "AHA Statistical Update Heart Disease and Stroke Statistics-2018 Update. A Report From the American Heart Association Circulation”. 2018; Vol.137, 20.03, pp.:e67-e492.

[2] R.-G. Lee, I.-C. Chou, C.-C. Lai, M.-H. Liu, M.-J. Chiu, “A Novel QRS detection algorithm to the analysis for heart rate variability of patients with sleep apnea," Biomed. Eng. Appl. Basis Comm., Vol.17, 2005, No 5, pp. 258-262.

[3] P. Drawz, D.C. Babineau, C. Brecklin, J. He, R. Kallem, E. Soliman, etc. "Heart Rate Variability is a Predictor of Mortality in CKD - A Report from the CRIC Study," American Journal of Nephrology, 2013, No 38, pp. 517-528.

[4] T. Benichou, B. Pereira, M. Mermillod, I. Tauveron, D. Pfabigan, etc. „Heart rate variability in type 2 diabetes mellitus: A systematic review and meta analysis," PLoS ONE, 2018, Vol. 13, No 4, pp. 1-19.

[5] K. Umetani, D. H. Singer, R. Mccraty, M. Atkinson, K. Umetani, D. H. Singer, R. Mccraty, M. Atkinson, "Twenty-Four Hour Time Domain Heart Rate Variability and Heart Rate: Relations to Age and Gender Over Nine Decades," JACC, Vol. 31, 1998, No. 3, pp. 593-601.

[6] V. Barauskiene, E. Rumbinaite, A. Karuzas, E. Martinkute, A. Puodziukynas, V. Barauskiene, E. Rumbinaite, A. Karuzas, E. Martinkute, A. Puodziukynas, "Importance of Heart Rate Variability in Patients with Atrial Fibrillation," J Cardiol Clin Res, Vol. 4, 2016, No. 6, pp. 1080-1086.

[7] B. Erynucu, M. Bilge, N. Guler, "Comparison of Heart Rate Variability and Treadmill Exercise Score in Patients with Stable Coronary Artery Disease," International Journal of Angiology IO, 2001, pp.178-182.

[8] Ö. Akyürek, E. Diker, M. Güldal, D.Oral, "Predictive Value of Heart Rate Variability for the Recurrence of Chronic Atrial Fibrillation after Electrical Cardioversion," Clin. Cardiol. Vol. 26, 2003, pp.196-200.

[9] M. Malik, A. J. Camm. Dynamic Electrocardiography. Blackwell Publ. Inc./Futura Division, New York, 2004.

[10] B. Malia S. Zuljb, R. Magjarevic, D. Miklavcic, T. Jarma, "Matlabbased tool for ECG and HRV analysis," Biomedical Signal Processing and Control, Vol. 10, 2014, pp. 108-116.

[11] G. Ernst, Heart Rate Variability. Springer-Verlag, London, 2014.

[12] D. M. Kumar, S.C. Prasannakumar, B. G. Sudarshan, D. Jayadevappa. "Heart Rate Variability Analysis: A Review" International Journal of Advanced Technology in Engineering and Science, Vol. 1, No. 6, 2013, pp. 9-24.

[13] V.S.B. Geetha, S. Sudha, "QRS complex detection in ECG of rescued victims in disaster zones," International Journal of Applied Engineering Research Vol. 10, 2015, No. 55, pp. 230-235.

[14] L. Murali, T. Manigandan, D. Chitra, S. V. Gopeka, "Mixed domain VLSI approach for ECG QRS complex detection," International Journal of Applied Engineering Research, Vol. 9, 2014, 24, pp. 27067-27081.

[15] M. Sibinagalingam, S. Vijayprasath, "Survey on ECG based heart rate variability analysis," International Journal of Applied Engineering Research, Vol. 10, 2015, No 20, pp.15305-15310.

[16] G. Georgieva-Tsaneva, M. Gospodinov, E. Gospodinova, "Simulation of Heart Rate Variability Data with Methods of Wavelet Transform," in B. Rachev, A. Smrikarov, Proc of 13th International Conference on Computer Systems and Technologies-CompSysTech'12, Vol. 630, ACM Press, New York, 2012, pp.306-312.
[17] L. Annetta, „The “I's” Have It: A Framework for Serious Educational Game Design," Review of General Psychology. American Psychological Association 2010, Vol. 14, No. 2, 105-112.

[18] M. Zyda, „From visual simulation to virtual reality to games,“ Computer, 2005, IEEE Computer Society, pp. 25-32.

[19] P. Noemí, S. Máximo „Educational Games for Learning. Universal Journal of Educational Research,“" 2014, Vol. 2, No 3, pp. 230-238.

[20] M. Prensky. "Digital game-based learning," ACM Computers in Entertainment, 2003, Vol 1 (1), Book Two.

[21] P, Vorderer, U. Ritterfeld, "Digital games," In Nabi R, Oliver M, eds. The SAGE handbook of media processes and effects. Thousand Oaks, CA: Sage, 2009.

[22] M. Malik, "Task Force of the European Society of Cardiology and the North American Society of Pacing and Electrophysiology. Heart rate variability: standards of measurement, physiological interpretation, and clinical use" Circulation, Vol. 93, 1996; pp. 1043-1065.

[23] N. Dey, A. Ashour, "Classification and Clustering in Biomedical Signal Processing," Advances in Bioinformatics and Biomedical Engineering, book series, IGI, 2016.

[24] H. Huikuri, P. Stein, "Clinical Application of Heart Rate Variability after Acute Myocardial Infarction," Frontiers in Physiology, 2012, Vol. 3, pp. 3-41.

[25] H.V. Huikuri, M.K. Linnaluoto, T. Seppanen, K.E. Airakinen, K.M. Kessler, J.T. Takkunen, R.J. Myerburg, "Circadian rhythm of heart rate variability in survivors of cardiac arrest," Am J Cardiol., Vol. 70, 1992, pp. 610-615.

[26] C. Raab, N. Wessel, A. Schirdewan, J. Kurths, "Large-Scale Dimension Densities for Heart Rate Variability Analysis," Computers in Cardiology, 2005, Vol.32, pp.985-987.

[27] G. Georgieva-Tsaneva, "QRS Detection Algorithm for long term Holter records," in B. Rachev, A. Smrikarov, Proc 14th International Conference on Computer Systems and Technologies-CompSysTech'13, Vol. 767, ACM, New York, 2013, pp. 112-119.

[28] G.Georgieva-Tsaneva, K. Tcheshmedjiev, "Denoising of Electrocardiogram Data with Methods of Wavelet Transform, "in B. Rachev, A. Smrikarov, Local Proceedings of 14th International Conference on Computer Systems and Technologies-CompSysTech'13, Ruse, Bulgaria, 2013, pp. $9-16$.

[29] G. Georgieva-Tsaneva, Application of Mathematical Methods for Analysis of Digital ECG Data. Information Technologies and Control, Year XIV, 2/2017, SAI, 2017, pp. 35-43.

[30] M. Malik, "Time-domain measurement of heart rate variability," Cardiac Electrophysiology Review, Vol. 3, 1997, pp. 329-334.

[31] H.-G. Kim, E.-J. Cheon, D.-S. Bai, Y. H. Lee, and B.-H. Koo, "Stress and Heart Rate Variability: A Meta-Analysis and Review of the Literature," Psychiatry Investig., 2018, Vol 15, No3, pp. 235-245.

[32] I. Gussak, C. Antzelevitch, Electrical Diseases of the Heart: Genetics, Mechanisms, Treatment, Prevention, Springer Science \& Business Media, 2008.

[33] L. Wang, X.Zhou, Y.Xing, S. Liang, "A Fast and Simple Adaptive Bionic Wavelet Transform: ECG Baseline Shift Correction", Cybernetics and Information Technologies, Vol. 16, 2016, No 6, pp. 6068 . 